\title{
Tribological Performance of Silahydrocarbons Used as Steel-Steel Lubricants under Vacuum and Atmospheric Pressure
}

\author{
Hai-Zhong Wang, ${ }^{1,2}$ Song-Wei Zhang, ${ }^{1,2}$ Dan Qiao, ${ }^{1,2}$ Da-Peng Feng, ${ }^{1}$ and Wei-Min Liu' \\ ${ }^{1}$ State Key Laboratory of Solid Lubrication, Lanzhou Institute of Chemical Physics, Chinese Academy of Sciences, \\ Lanzhou 730000, China \\ ${ }^{2}$ Graduate University of the Chinese Academy of Sciences, Beijing 100049, China
}

Correspondence should be addressed to Da-Peng Feng; dpfeng@licp.cas.cn and Wei-Min Liu; wmliu@licp.cas.cn

Received 6 March 2014; Accepted 2 April 2014; Published 16 April 2014

Academic Editor: Jun Yang

Copyright (C) 2014 Hai-Zhong Wang et al. This is an open access article distributed under the Creative Commons Attribution License, which permits unrestricted use, distribution, and reproduction in any medium, provided the original work is properly cited.

The silahydrocarbons of tetraalkylsilanes with different substituted alkyl groups (named as $\mathrm{SiCH}$ ) were synthesized and evaluated as lubricants for steel-steel contacts by a home-made vacuum four-ball tribometer (VFBT-4000) under atmospheric pressure and under vacuum pressure $\left(5 \times 10^{-4} \mathrm{~Pa}\right)$. The $\mathrm{SiCH}$ oils possess better thermal stability, low temperature fluidity, and lower saturated vapor pressure than those of multialkylatedcyclopentanes (MACs). The tribological performances of the SiCH oils are also superior to those of MACs and PFPE-Z25 in terms of friction-reduction ability and antiwear capacity under sliding friction at vacuum. The SEM/EDS and XPS results reveal that the boundary lubricating film consisting of (-O-Si-R-) ${ }_{n}$ compounds is formed by tribochemical reactions and serious adhesion wear under atmospheric pressure and the film consisting of $(-\mathrm{Si}-\mathrm{R}-\mathrm{Si}-)_{n}$ compounds is formed on the worn surface under vacuum pressure.

\section{Introduction}

The use of space satellites for communication, navigation, and defense is becoming more and more important. High costs for both construction and launch satellites are driving the need to extend the service life of these satellites from the current 5 to 8 years to 10 years and even for a longer period. According to NASA, many mechanical failures in spacecraft were caused by tribological problems [1-6]. Thus, the improvement of lubrication and antiwear performance for the mechanical systems is the key to extend the service life of satellites and spacecrafts. The synthetic liquid lubricants have been very commonly used in aerospace equipment for many years. And low vapor pressure, low pour point, good thermal stability, and good lubrication properties, particularly, good boundary lubrication performance and low wear formation rates, are crucial physicochemical and tribological properties which is to be ensured for aerospace devices $[7,8]$. The majority of current aerospace applications use mineral oils, perfluoropolyalkylethers (PFPEs), or synthetic hydrocarbons, such as multialkylatedcyclopentanes (MACs) and polyalphaolefins (PAO) $[9,10]$. PFPEs are the mostly used liquid lubricants for aerospace mechanisms but suffer from poor boundary lubrication capability, the incompatibility with conventional additives, the catalytic degradation, and so forth [11, 12]. MACs and PAO are of limited use at low temperature and in vacuum.

Recently, a relatively new type of space lubricants (i.e., silahydrocarbons) has been developed. These lubricants contain only silicon carbon and hydrogen [8]. Early studies [1316] have shown that silahydrocarbons have significantly lower melting points compared to corresponding hydrocarbons. Silahydrocarbons are superior to mineral oils and synthetic hydrocarbons in both thermal and oxidative stabilities as well as viscosity-temperature behaviour. They possess unique friction-reducing and antiwear properties while retaining the ability to solubilize conventional additive, which is an attractive future lubrication requirement for aircraft and aerospace mechanisms, particularly for low temperature and high vacuum applications use in space. 
The aim of this work was to study the physical properties of silahydrocarbons of tetraalkylsilanes with different substituted alkyl groups (named as $\mathrm{SiCH}$ ) and evaluate the tribological performance of $\mathrm{SiCH}$ as liquid lubricants for steel-steel contacts by a vacuum four-ball tribometer under atmospheric pressure and under vacuum pressure. For comparison, the tribological properties of two aerospace lubricants, namely, PFPE-Z25 (under the trade name "Z25") and MACs, were also investigated under the same circumstances.

\section{Experimental}

The SiCH oils and MACs were synthesized according to the references in laboratory [17-19], and the molecular structures of the $\mathrm{SiCH}$ oils were characterized by an intensity fluctuation spectroscopy $66 \mathrm{v} / \mathrm{s}$ Fourier transformation infrared (FTIR) spectroscopy and $400 \mathrm{MHz}$ Bruker-400 FT nuclear magnetic resonance spectroscopy (NMR) spectrometers. PFPE-Z25 is commercially provided by Fomblin Inc., in the US, which is used in the aviation and military industries.

The molecular structures of the SiCH oils and MACs are shown in Figure 1; several typical physical properties of the $\mathrm{SiCH}$ oils and MACs are shown in Table 1. The kinematic viscosities of the lubricants were measured using an SVM3000 Stabinger viscometer at different temperatures according to ASTM D445 designation. The saturated vapor pressure of the lubricants was evaluated on a home-made vacuum grease saturated vapor pressure tribometer by the method of evaporation. Thermogravimetric analysis (TGA) was performed on a Perkin-Elmer TGA-7 conducted in nitrogen atmosphere from $20^{\circ} \mathrm{C}$ to $600^{\circ} \mathrm{C}$ at a heating speed of $10^{\circ} \mathrm{C} / \mathrm{min}$. The evaporation weight loss of the lubricants was evaluated in a vacuum oven under approximately $5 \times 10^{-3} \mathrm{~Pa}$ at $125^{\circ} \mathrm{C}$ (the results were shown in Table 2).

In order to test the anticorrosion properties of the $\mathrm{SiCH}$ oil to metal substrates in the presence of water, the corrosion tests were carried out in an environmental chamber under the hot and humid condition according to standard method of ASTM D130-94. The polished GCr15 bearing steel (SAE52100) block was used as the substrate, and the testing conditions are as follows: test temperature of $100^{\circ} \mathrm{C}, 80 \%$ relative humidity, and duration of $24 \mathrm{~h}$.

The tribological performances of the $\mathrm{SiCH}$ oils, MACs, and PFPE-Z25 as lubricants for steel-steel contacts were evaluated on a home-made vacuum four-ball tribometer (VFBT4000) under atmospheric pressure and under vacuum pressure $\left(5 \times 10^{-4} \mathrm{~Pa}\right)$. The vacuum four-ball tribometer which was designed and manufactured by the State Key Laboratory of Solid Lubrication, Lanzhou Institute of Chemical Physics, Chinese Academy of Sciences, based on the configuration of a traditional four-ball tribometer, was employed. As shown schematically in Figure 2, the vacuum chamber was evacuated by using a series of a turbomolecular pump and a mechanical pump. The tribological characteristics of liquid lubricants for aerospace applications were evaluated by this tribometer under the pressures of $5 \times 10^{-4} \mathrm{~Pa}$. It can also be run at lower vacuum (about $10 \mathrm{~Pa}$ ) and at atmospheric pressure with air or nitrogen.

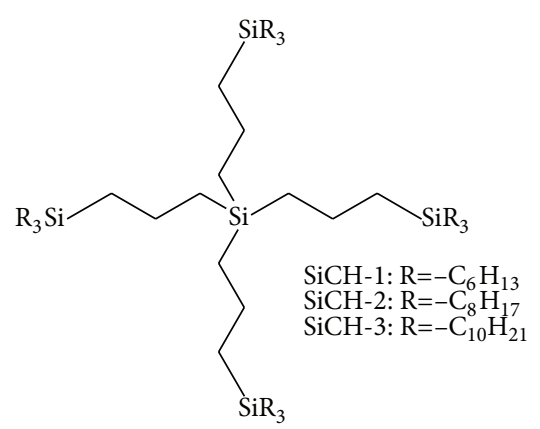

FIGURE 1: Molecular structures of the prepared $\mathrm{SiCH}$ oils.

All tribological performance tests were performed under the load of $392 \mathrm{~N}$ with a rotating speed of $1450 \mathrm{rpm}$ at $25^{\circ} \mathrm{C}$ for $30 \mathrm{~min}$. The steel balls (diameter $12.7 \mathrm{~mm}$, hardness HRC 59 to 61) were made of GCr15 bearing steel (SAE 52100). Before and after each test, test specimens were ultrasonically cleaned in petroleum ether (normal alkane with a boiling point of $60 \sim 90^{\circ} \mathrm{C}$ ). For each sample, three tests were conducted to minimize data scattering. At the end of each test, the wear scar diameters of the three lower balls were measured with an optical microscope with an accuracy of $0.01 \mathrm{~mm}$, and then the average wear scar diameter of the three identical tests was calculated as the wear scar diameter (WSD) in this paper. The friction coefficients were recorded automatically with a computer equipped with a four-ball tribometer.

Experiments using a scanning electron microscope with a Kevex energy dispersive X-ray analyzer attachment (SEM/EDS) and an X-ray photoelectron spectrometer (XPS) were conducted to examine the morphology and chemical composition of the wear scars and the possible tribochemical changes involved in the sliding process. The SEM/EDS analysis was performed on a JSM-5600LV SEM. The XPS analysis was carried out on a PHI-5702 multifunctional Xray photoelectron spectroscope, with $\mathrm{Al}-\mathrm{K} \alpha$ radiation as the exciting source. The binding energies of the target elements were determined at a pass energy of $29.35 \mathrm{eV}$ with resolution of approximately $\pm 0.3 \mathrm{eV}$, with the binding energy of carbon (C1s: $284.8 \mathrm{eV}$ ) as the reference.

\section{Results and Discussion}

3.1. Physical Properties of Silahydrocarbon Lubricants. The molecular structures of $\mathrm{SiCH}$ are shown in Figure 1 and are analyzed by infrared spectroscopy (IR) and proton nuclear magnetic resonance $\left({ }^{1} \mathrm{H}-\mathrm{NMR}\right)$. It can be seen that the molecular structure of $\mathrm{SiCH}$ resembles branched macromolecules (tree-like structure); the substituted alkyl (-R) in the molecular structures was selected as hexyl $\left(-\mathrm{C}_{6} \mathrm{H}_{13}\right)$, $\operatorname{octyl}\left(-\mathrm{C}_{8} \mathrm{H}_{17}\right)$, and decyl $\left(-\mathrm{C}_{10} \mathrm{H}_{21}\right)$, named as $\mathrm{SiCH}-1, \mathrm{SiCH}-$ 2 , and $\mathrm{SiCH}-3$, respectively.

As an example, the findings of $\mathrm{SiCH}-3$ are shown as follows [IR (KBr film), $v \max / \mathrm{cm}^{-1}$, Figure 3(a)]: C-H stretching vibration bands appear at $2956 \mathrm{~cm}^{-1}, 2921 \mathrm{~cm}^{-1}$, and $2853 \mathrm{~cm}^{-1}$; C-H band modes at $1466 \mathrm{~cm}^{-1}$ and $1378 \mathrm{~cm}^{-1}$, and the band at $720 \mathrm{~cm}^{-1}$ is the- $\left(\mathrm{CH}_{2}\right)_{7}$-rocking vibration; $\mathrm{Si}-\mathrm{C}$ 
TABle 1: Physical properties of these liquid lubricants.

\begin{tabular}{|c|c|c|c|c|c|c|c|c|}
\hline \multirow{3}{*}{ Lubricants } & \multicolumn{8}{|c|}{ Properties } \\
\hline & \multirow{2}{*}{$\begin{array}{l}\text { Saturated vapor } \\
\text { pressure/Torr, } 25^{\circ} \mathrm{C}\end{array}$} & \multicolumn{4}{|c|}{ Kinematic viscosity $\left(\mathrm{mm}^{2} \cdot \mathrm{s}^{-1}\right)$} & \multirow{2}{*}{ Density $/ \mathrm{kg} \cdot \mathrm{m}^{-3}$} & \multirow{2}{*}{$\begin{array}{c}\text { TGA (onset decompositon } \\
\text { temperature } /{ }^{\circ} \mathrm{C} \text { ) }\end{array}$} & \multirow{2}{*}{ Pour point $/{ }^{\circ} \mathrm{C}$} \\
\hline & & $-20^{\circ} \mathrm{C}$ & $40^{\circ} \mathrm{C}$ & $100^{\circ} \mathrm{C}$ & VI & & & \\
\hline $\mathrm{SiCH}-1$ & $3.4 \times 10^{-9}$ & 2180 & 73.8 & 13.2 & 184 & 843.2 & 362 & $<-55$ \\
\hline $\mathrm{SiCH}-2$ & $6.2 \times 10^{-10}$ & 2621 & 86.6 & 15.4 & 189 & 851.0 & 387 & $<-55$ \\
\hline $\mathrm{SiCH}-3$ & $2.0 \times 10^{-10}$ & 3025 & 97.2 & 17.2 & 194 & 857.4 & 394 & $<-55$ \\
\hline MACs & $1.7 \times 10^{-8}$ & 2550 & 58.1 & 8.8 & 140 & 847.1 & 385 & -55 \\
\hline PFPE-Z25 & $2.9 \times 10^{-12}$ & - & 160.5 & 48.4 & 350 & 1850.8 & 383 & -73 \\
\hline
\end{tabular}

TABLE 2: Evaporation weight loss of the SiCH oils, MACs, and PFPE$\mathrm{Z} 25$ under vacuum pressure $\left(24 \mathrm{~h}\right.$ at $\left.125^{\circ} \mathrm{C}, 5 \times 10^{-3} \mathrm{~Pa}\right)$.

\begin{tabular}{lc}
\hline Lubricants & Evaporation weight loss (wt.\%) \\
\hline SiCH-1 & 0.91 \\
SiCH-2 & 0.63 \\
SiCH-3 & 0.28 \\
MACs & 2.32 \\
PFPE-Z25 & 0.23
\end{tabular}

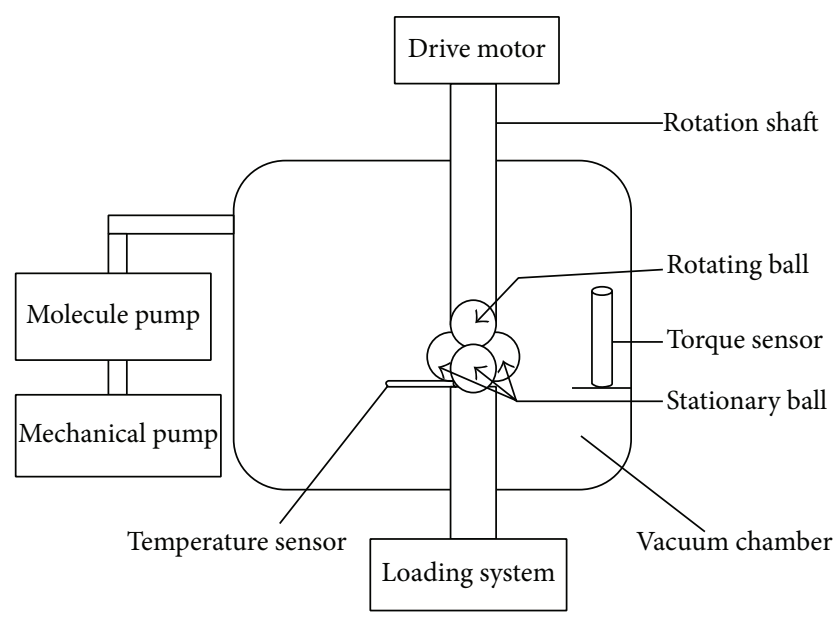

FIGURE 2: Schematic illustration of the vacuum four-ball tribometer.

stretching vibration bands at $1411 \mathrm{~cm}^{-1}, 1176 \mathrm{~cm}^{-1}, 1139 \mathrm{~cm}^{-1}$, and $895 \mathrm{~cm}^{-1}$. ${ }^{1} \mathrm{H}$-NMR (chloroform-d, Figure $3(\mathrm{~b})$ ) is as follows: 1.29 [b, $152 \mathrm{H}$ ], 0.91 to 0.89 [b, $36 \mathrm{H}$ ], and 0.76 to 0.50 $[\mathrm{m}, 40 \mathrm{H}]$. Both of the IR and ${ }^{1} \mathrm{H}$ NMR results proved that the synthetic compound has the designed molecular structure.

Table 1 shows several physical properties of $\mathrm{SiCH}$, MACs, and PFPE-Z25 oils. It can be seen that the three kinds of $\mathrm{SiCH}$ oils have lower saturated vapor pressure compared with MACs, but higher than that of PFPE-Z25 oil. The viscosity indices (named as $V I$ ) of the three $\mathrm{SiCH}$ oils are similar. The kinetic viscosity increases with the carbon number increase of the substituted alkyl groups within the $\mathrm{SiCH}$ molecular structures; the viscosity of $\mathrm{SiCH}-1$ is the smallest among the three $\mathrm{SiCH}$ oils at $-20^{\circ} \mathrm{C}$, which are also superior to MACs.
Table 1 reveals that the three $\mathrm{SiCH}$ oils also exhibit better low temperature fluidity, with their pour points lower than $-55^{\circ} \mathrm{C}$. By contrast, MACs could not flow under $-55^{\circ} \mathrm{C}$. These results indicate that the $\mathrm{SiCH}$ synthetic oils can be used in a wide temperature range and especially exhibit good fluidity under low temperature conditions.

Table 1 also presents the thermal stability results of these oils. $\mathrm{SiCH}-3$ exhibits the highest thermal decomposition temperature among all the liquid lubricants in this study. Moreover, the thermal stability of the $\mathrm{SiCH}$ oils increases with an increase in the chain length of the substituted alkyl within the molecular structures.

Meanwhile, the evaporation weight loss results of these oils at $125^{\circ} \mathrm{C}$ with 24 hours under vacuum pressure (nearly $5 \times$ $10^{-3} \mathrm{~Pa}$ ) are listed in Table 2. The vacuum evaporation weight loss of SiCH-3 is the smallest among the oils in this study, which is close to that of the PFPE-Z25 oil; it is also indicated that the lubricant with longer chain length structure would show lower volatility. The results show that all of the $\mathrm{SiCH}$ oils are superior to the synthetic oil of MACs in the evaporation weight loss, which is due to the tree-like molecular structure of $\mathrm{SiCH}$.

The corrosion results of SiCH-3 with steel were selected to describe the anticorrosion property in Figure 4 because the $\mathrm{SiCH}$ oils possess the similar anticorrosion properties. It can be seen that there is no corrosion on bearing steel with the oils under the hot and humidity conditions, and no corrosion could be produced during the friction process.

3.2. Tribological Performance. Figures 5 and 6 present the curves of friction coefficient (Figures 5(a) and 5(b)) and the average friction coefficient (Figure 6) lubricated with the $\mathrm{SiCH}$ oils, MACs, and PFPE-Z25 by a vacuum four-ball tribometer under atmospheric pressure and under vacuum pressure, respectively. The wear scar diameters of these lubricants by this experiment are shown in Figure 7.

It can be seen from Figures 5(a) and 6 that MACs show the steadiest friction curves and the lowest average friction coefficient (approximately 0.08 ) compared with the $\mathrm{SiCH}$ oils and PFPE-Z25 under atmospheric pressure. It is also seen that $\mathrm{SiCH}$ oils with different chain of the substituted alkyl groups exhibit different tribological behavior. The friction coefficient decreases along with the increase of carbon number in the alkyl chain under this tested condition. The curves of friction 


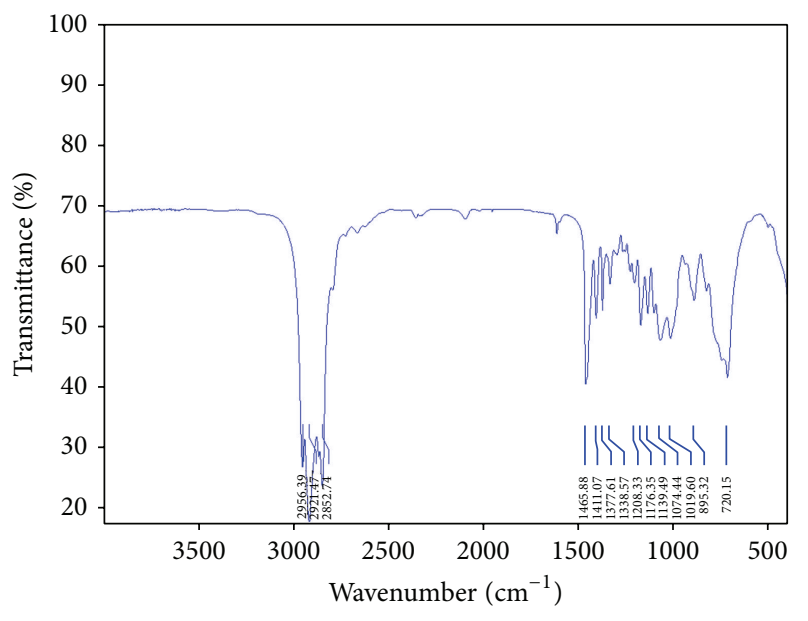

(a)

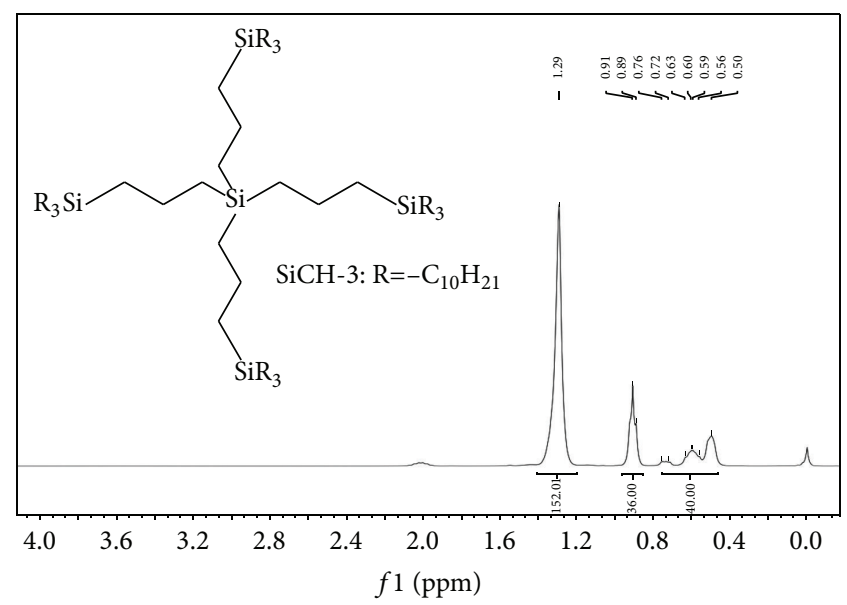

(b)

Figure 3: FTIR spectrum (a) and ${ }^{1} \mathrm{H}-\mathrm{NMR}$ spectrum (b) of the $\mathrm{SiCH}-3$ oil.

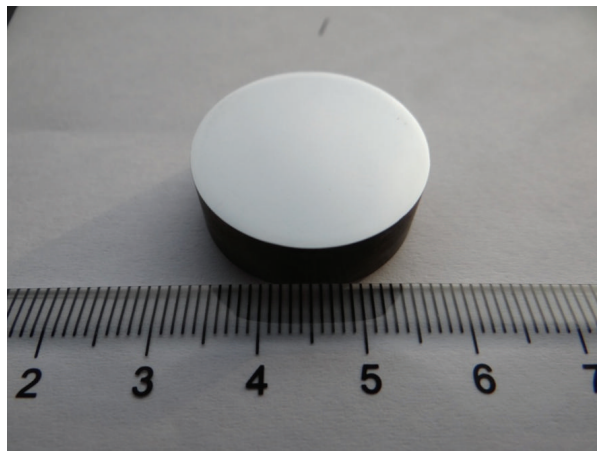

(a)

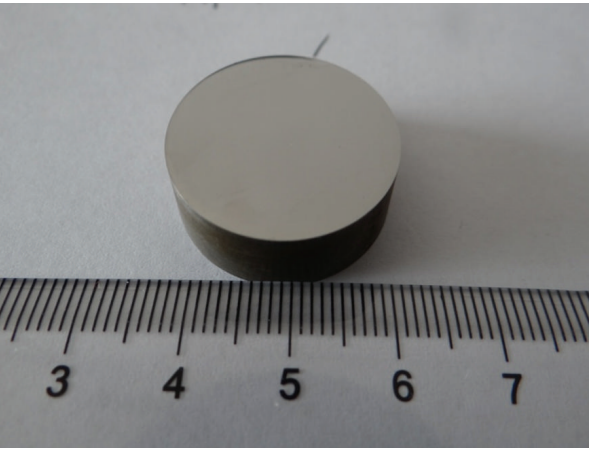

(b)

FIGURE 4: The corrosion capability test of SiCH-3 oils on steel SAE 52100 ((a) before corrosion test; (b) after corrosion test) (100 ${ }^{\circ} \mathrm{C}, 24 \mathrm{~h}$, and relative humidity $80 \%)$.

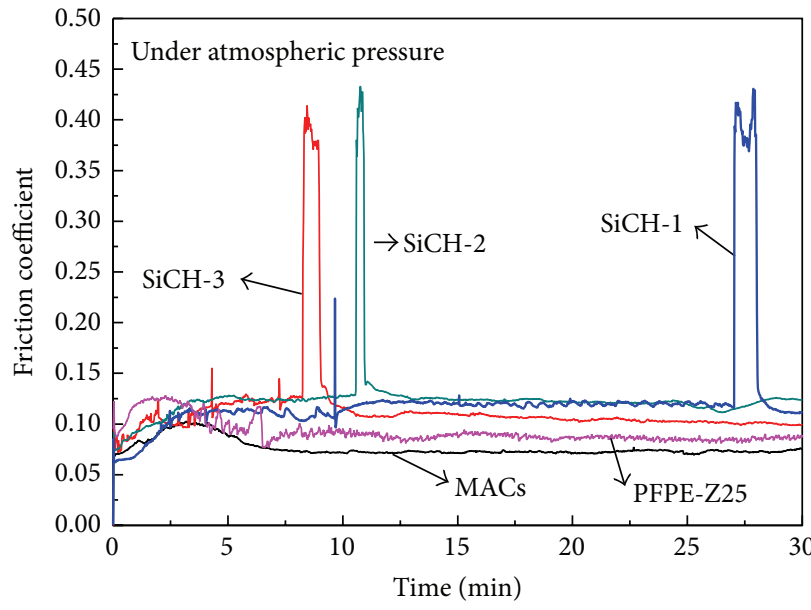

(a)

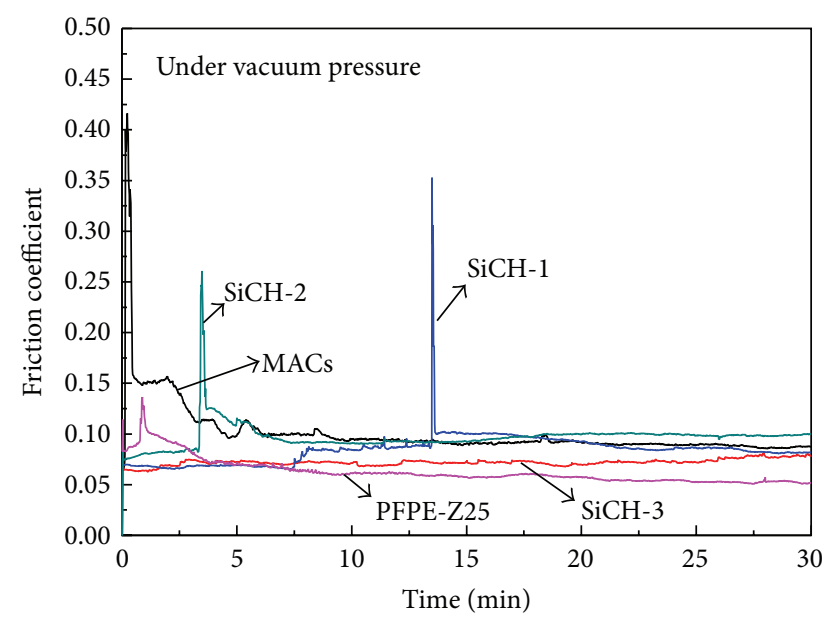

(b)

FIGURE 5: The friction coefficient curves of the lubricants for steel-steel contacts under atmospheric pressure (a) and under vacuum pressure (b) $(392 \mathrm{~N}, 30 \mathrm{~min} 1450 \mathrm{rpm}$, and four-ball tribometer). 


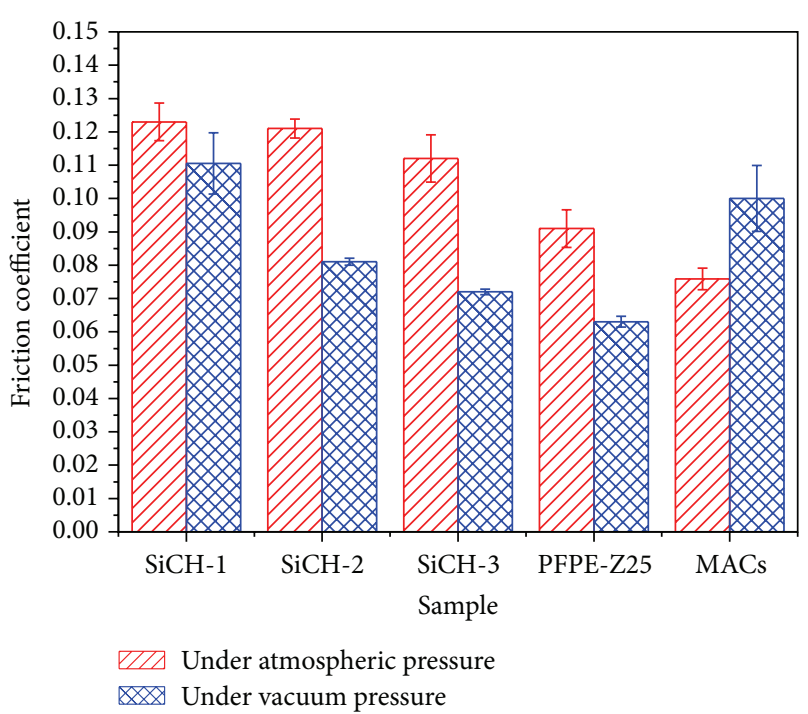

FIGURE 6: The average friction coefficients of lubricants for steelsteel contacts under atmospheric pressure and under vacuum pressure (392 N, $30 \mathrm{~min}, 1450 \mathrm{rpm}$, and four-ball tribometer).

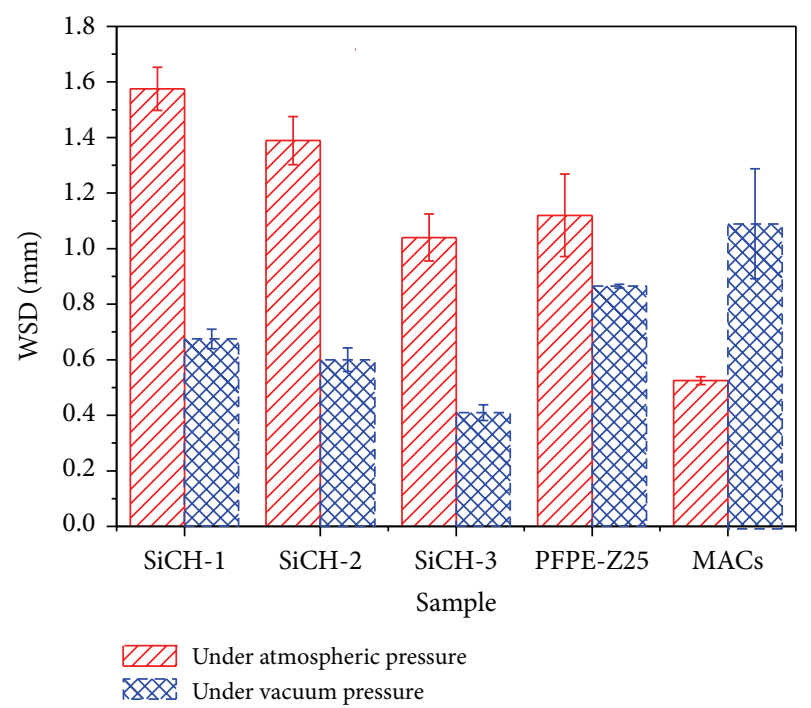

FIGURE 7: Wear scar diameters of SiCH oils for steel-steel contacts under atmospheric pressure and under vacuum pressure $(392 \mathrm{~N}$, $30 \mathrm{~min}, 1450 \mathrm{rpm}$, and four-ball tribometer).

coefficient of the $\mathrm{SiCH}$ oils are all instable and show transient seizure-like high friction [20-22] and transient dry friction or abrasive wear occurred on the worn surface. This result should be explained as that some compounds, for example, $\mathrm{SiO}_{x}$, might be produced on the steel surfaces lubricated by the $\mathrm{SiCH}$ oils during the high friction period, which facilitate returning to a low-friction period. Meanwhile, comparing the antiwear performances of these lubricants under atmospheric pressure as seen in Figure 7, MACs exhibit the smallest WSD. In addition, the antiwear property of $\mathrm{SiCH}-3$ is superior to that of PFPE-Z25 and the WSD lubricated by SiCH3 is the smallest among the three $\mathrm{SiCH}$ oils. This finding indicates that the tribological properties of the $\mathrm{SiCH}$ oils would improve with an increase in the chain length of the substituted alkyl in case this tendency continues.

The curves of friction coefficient results of these lubricants under vacuum pressure are shown in Figure 5(b). SiCH3 exhibits the steadiest curves of friction coefficient, and did not show transient seizure-like high friction during the entire sliding process under vacuum pressure. The MACs show higher average friction under vacuum pressure than that under atmospheric pressure, which is contrary to the results of other lubricants. It can be seen from Figure 7 that $\mathrm{SiCH}$ 3 also shows the smallest wear scar diameter as lubricant for steel-steel contacts among the three $\mathrm{SiCH}$ oils, which is benefited from the longer chain in the molecular structure, which indicating that the antiwear property of $\mathrm{SiCH}-3$ is superior to that of PFPE-Z25 and MACs under vacuum pressure. It is noticeable that the average friction coefficient and WSD of MACs are the maximum under vacuum pressure, which is contrary to the results obtained under atmospheric pressure. The tribochemical reactions of the $\mathrm{SiCH}$ oils with the steel surface are different under atmospheric pressure and the vacuum pressure; thus, different boundary films might be formed during the sliding friction under different conditions.

3.3. Surface Analysis. Since SEM/EDS and XPS analyses of the worn scars lubricated by $\mathrm{SiCH}$ oils with different substituted alkyl groups show similar results, we describe here the emphasis of the results of SiCH-3. Figure 8 shows the typical SEM images and elemental distributions of silicon on the wear scar surfaces lubricated by $\mathrm{SiCH}-3$ under atmospheric pressure and under vacuum pressure, respectively. The wear scar (Figure 8(d)) that was lubricated by $\mathrm{SiCH}$ 3 under vacuum pressure is smaller and the worn surface is smooth along with mild scuffing. However, wider wear scar is shown in Figure 8(a) after the lubrication by $\mathrm{SiCH}-3$ under the atmospheric pressure with serious adhesion wear (Figure $8(b)$ ). The results of wear scar morphologies on the worn surfaces (Figures 8(b) and 8(e)) are consistent with those of the elemental distributions of silicon (Figures 8(c) and $8(\mathrm{f})$ ), implying that silicon is enriched on the wear track and the concentration of silicon is clearly higher on the worn surface lubricated under vacuum friction condition than that under atmospheric friction condition.

The SEM/EDS analysis shows that the elemental distribution of silicon on the worn surface lubricated under vacuum friction condition is different from that under atmospheric friction condition, which explains the different tribological performances of the oils under atmospheric pressure and under vacuum pressure.

XPS analysis is used to further clarify the chemical states of the typical elements on the wear scar surfaces lubricated by the $\mathrm{SiCH}$ oils. XPS results indicate that complicated tribochemical reaction occurred during friction. Figure 9 shows the XPS spectra of typical elements of $\mathrm{O}$ and $\mathrm{Si}$ on the worn surfaces lubricated by $\mathrm{SiCH}-3$ under atmospheric pressure and under vacuum pressure. Under atmospheric pressure, it can be seen that the binding energy of Si2p appears at $102.3 \mathrm{eV}$, combining with the binding energy of O1s at $531.3 \mathrm{eV}$, which 


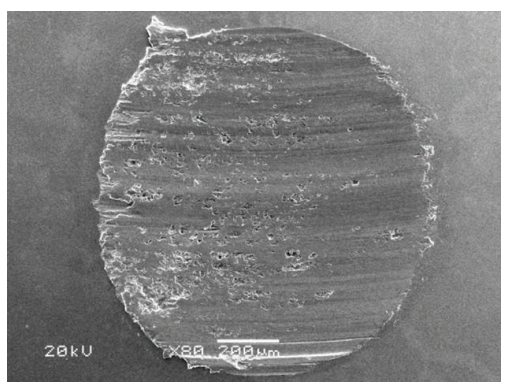

(a)

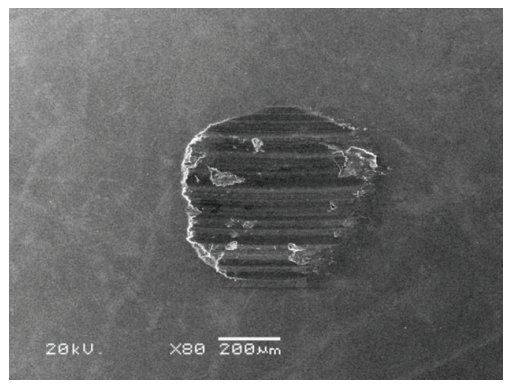

(d)

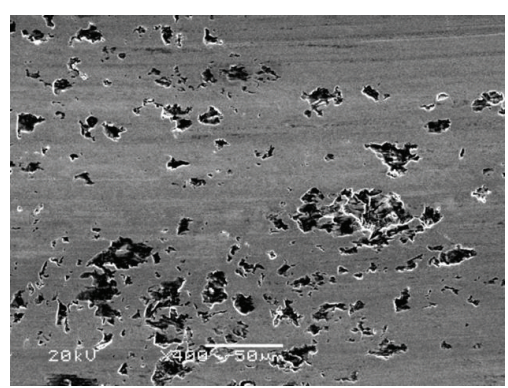

(b)

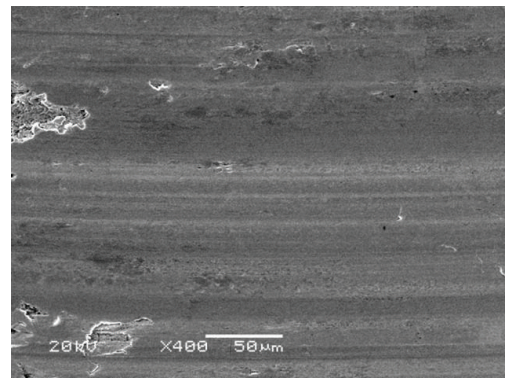

(e)

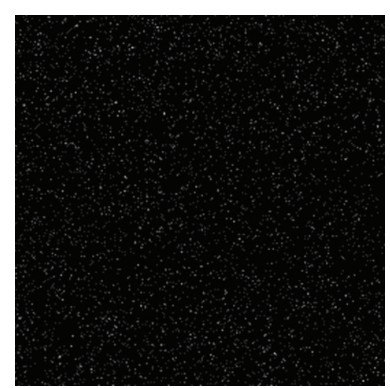

(c)

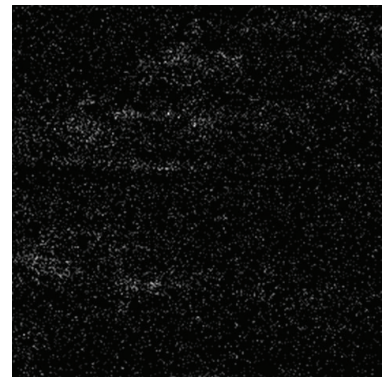

(f)

Figure 8: SEM images ((a), (b), (d), and (e)) and elemental distribution of Si ((c) and (f)) on the worn surface of the steel ball lubricated by $\mathrm{SiCH}-3$ under atmospheric pressure $((\mathrm{a}),(\mathrm{b})$, and $(\mathrm{c}))$ and under vacuum pressure $((\mathrm{d}),(\mathrm{e})$, and (f)).

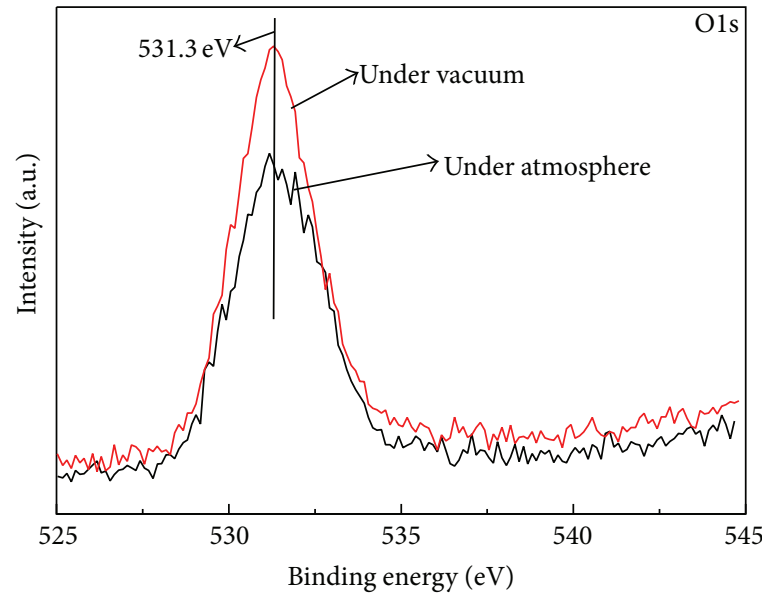

(a)

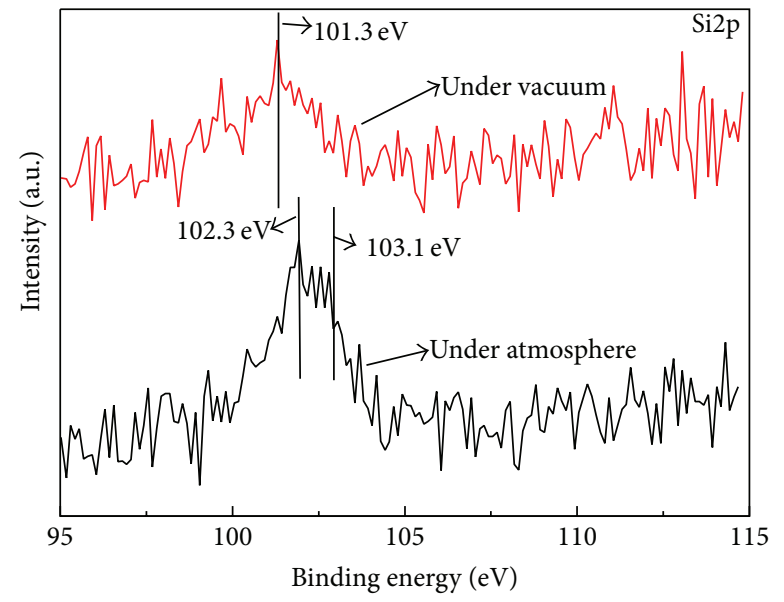

(b)

FIGURE 9: XPS spectra of O1s (a) and Si2p (b) of the worn surface lubricated by SiCH-3 under atmospheric pressure and under vacuum pressure.

is corresponding to the compound of (-O-Si-R- $)_{n}$ [23]. Moreover, the $\mathrm{Si} 2 \mathrm{p}$ peak at $103.1 \mathrm{eV}$ is ascribed to $\mathrm{SiO}_{2}$. Lubricating with $\mathrm{SiCH}$ oil under atmospheric condition, much oxygen dissolving in the oil participated in the tribochemical reaction to produce some oxidative compounds.

However, the main binding energy of Si2p $(101.7 \mathrm{eV})$ under vacuum pressure is different with respect to that of $\mathrm{Si} 2 \mathrm{p}(102.3 \mathrm{eV})$ under atmospheric pressure, which is characterized by the compound of $(-\mathrm{Si}-\mathrm{R}-\mathrm{Si})_{n}$ with lack of oxygen. And abrasive wear is observed on the worn surface under vacuum pressure during the friction process, which can be seen from the SEM images (Figures 8(d) and 8(e)). There is few flaking on the worn track, which presents that $\mathrm{SiCH}$ performs excellent lubricating properties under vacuum pressure.

On the basis of the above results, it illustrates that different tribochemical reactions occurred on the worn surface lubricated by the $\mathrm{SiCH}$ oils when the sliding friction experiments 
were carried out under different conditions. The boundary film consisted of the compound (-O-Si-R- $)_{n}$ and $\mathrm{SiO}_{2}$ is formed by the tribochemical reaction and serious adhesion wear under atmospheric pressure, whereas the compound of $(-\mathrm{Si}-\mathrm{R}-\mathrm{Si})_{n}$ is formed on the worn surface by abrasive wear under vacuum pressure during the sliding friction with the $\mathrm{SiCH}$ oils.

\section{Conclusions}

Sliding friction experiments of $\mathrm{SiCH}$ synthetic oils as lubricants for steel-steel contacts were carried out on a vacuum four-ball tribometer under different atmospheric pressure. Based on the above experimental results, the following conclusions are drawn.

(i) The $\mathrm{SiCH}$ synthetic oils were prepared and they possess good thermal stability, low temperature fluidity, and lower saturated vapor pressure, denoting that they are superior to that of MACs as aerospace lubricants.

(ii) The $\mathrm{SiCH}$ with decyl group substituted shows the best tribological behaviour among the three $\mathrm{SiCH}$ synthetic oils for steel-steel contacts under vacuum pressure and is superior to those of MACs and PFPE-Z25 in terms of friction-reduction ability and antiwear capacity.

(iii) The SEM/EDS and XPS results reveal that the tribochemical reactions of $\mathrm{SiCH}$ oils with the steel surface are different under atmospheric pressure and under vacuum pressure during the sliding friction. The boundary lubricating film that consisted of the compound of (-O-Si-R- $)_{n}$ and $\mathrm{SiO}_{2}$ is formed by the tribochemical reaction and serious adhesion wear under atmospheric pressure, whereas the compound of $(-\mathrm{Si}-\mathrm{R}-\mathrm{Si})_{n}$ is formed on the worn surface by abrasive wear under vacuum pressure.

\section{Conflict of Interests}

The authors declare that there is no conflict of interests regarding the publication of this paper.

\section{Acknowledgments}

The authors acknowledge financial support from the National Key Basic Research Program of China (973) (2013CB632301) and the National Natural Science Foundation of China (51175492).

\section{References}

[1] T. Krantz and F. Oswald, "Wear of spur gears having a dithering motion andlubricated with a perfluorinated polyether grease," NASA Technical Memorandum 215008, 2007.

[2] L. J. Gschwender, C. E. Snyder Jr., M. Massey, and S. Peterangelo, "Improved liquid/grease lubricants for space mechanism," Lubrication Engineering, vol. 56, no. 12, pp. 25-31, 2000.
[3] W. J. Bartz, "Synthetic hydraulic fluids for high performance applications," Lubrication Engineering, vol. 56, no. 10, pp. 42-53, 2000.

[4] R. Fusaro, "Preventing spacecraft failures due to tribological problems," NASA Technical Memorandum 210806, 2001.

[5] D. N. Baker, "Effects of the Sun on the Earth's environment," Journal of Atmospheric and Solar-Terrestrial Physics, vol. 62, no. 17-18, pp. 1669-1681, 2000.

[6] D. N. Baker, "What is space weather?" Advances in Space Research, vol. 22, no. 1, pp. 7-16, 1998.

[7] E. V. Zaretsky, "Liquid lubrication in space," Tribology International, vol. 23, no. 2, pp. 75-93, 1990.

[8] W. R. Jones, B. A. Shogrin, and M. J. Jansen, "Research on liquid lubricants for space mechanisms," Journal of Synthetic Lubrication, vol. 17, no. 2, pp. 109-122, 2000.

[9] S. S. Hirsch and W. J. Bailey, "Base-catalyzed alkylation of cyclopentadiene rings with alcohols and amines," Journal of Organic Chemistry, vol. 43, no. 21, pp. 4090-4094, 1978.

[10] J. Sicre, P. Vergne, P. Prat, and M. Pochard, "New consideration on fluid lubricants for spacecraft applications," in Proceedings of the 6th European Space Mechanism and Tribology Symposium, pp. 169-176, Zurich, Switzerland, 1995.

[11] E. Cosmacini and V. Veronesi, "A study of the tribological behaviour of perfluoro-polyethers," Wear, vol. 108, no. 3, pp. 269-283, 1986.

[12] M. Masuko, I. Fujinami, and H. Okabe, "Lubrication performance of perfluoropolyalkylethers under high vacuum," Wear, vol. 159, no. 2, pp. 249-256, 1992.

[13] C. Tamborski, G. J. Chen, D. R. Anderson, and C. E. Snyder Jr., "Synthesis and properties of silahydrocarbons, a class of thermally stable, wide liquid range fluids," Industrial and Engineering Chemistry Product Research and Development, vol. 22, no. 2, pp. 172-178, 1983.

[14] C. E. Snyder Jr, L. J. Gschwender, B. B. Randolph et al., "Research and development of low-volatility long life silahydrocarbonbased liquid lubricants for space," Lubrication Engineering, vol. 48, pp. 325-328, 1992.

[15] K. J. L. Paciorek, J. G. Shih, R. H. Kratzer, B. B. Randolph, and C. E. Snyder Jr., "Polysilahydrocarbon synthetic fluids. 1. Synthesis and characterization of trisilahydrocarbons," Industrial and Engineering Chemistry Research, vol. 29, no. 9, pp. 1855-1858, 1990.

[16] P. A. Bessette, "Advanced lubricants based on multiply alkylated cyclopentane, polyphenyl ether and silahydrocarbon," NLGI Spokesman, vol. 66, no. 11, pp. 20-24, 2003.

[17] L. P. Kazimiera, R. E. Pratt, and K. J. L. Paciorek, “Trisilahydrocarbon lubricants," United States patent 4788312, 1988.

[18] K. J. L. Paciorek, J. G. Shih, R. H. Kratzer, B. B. Randolph, and C. E. Snyder Jr., "Polysilahydrocarbon synthetic fluids. 2. Synthesis and characterization of tetrasilahydrocarbons," Industrial \& Engineering Chemistry Research, vol. 30, no. 9, pp. 2191-2194, 1991.

[19] C. G. Venier and E. W. Casserly, "Multiply-alkylated cyclopentanes (MACs). A new class of synthesized hydrocarbon fluids," Lubrication Engineering, vol. 47, no. 7, pp. 586-591, 1991.

[20] S. W. Zhang, L. T. Hu, D. P. Feng, and H. Z. Wang, "Anti-wear andfriction-reduction mechanism of $\mathrm{Sn}$ and $\mathrm{Fe}$ nanoparticles as additives of multialkylated cyclopentanes under vacuum condition," Vacuum, vol. 87, pp. 75-80, 2013.

[21] M. Masuko, H. Mizuno, A. Suzuki, S. Obara, and A. Sasaki, "Lubrication performance of multialkylatedcyclopentane oils 
for sliding friction of steel under vacuum condition," Journal of Synthetic Lubrication, vol. 24, no. 4, pp. 217-226, 2007.

[22] S. W. Zhang, L. T. Hu, H. Z. Wang, and D. P. Feng, "The anti-seizure effect of Ag nanoparticles additive in multialkylatedcyclopentanes oil under vacuum condition," Tribology International, vol. 55, pp. 1-6, 2012.

[23] http://srdata.nist.gov/xps/. 

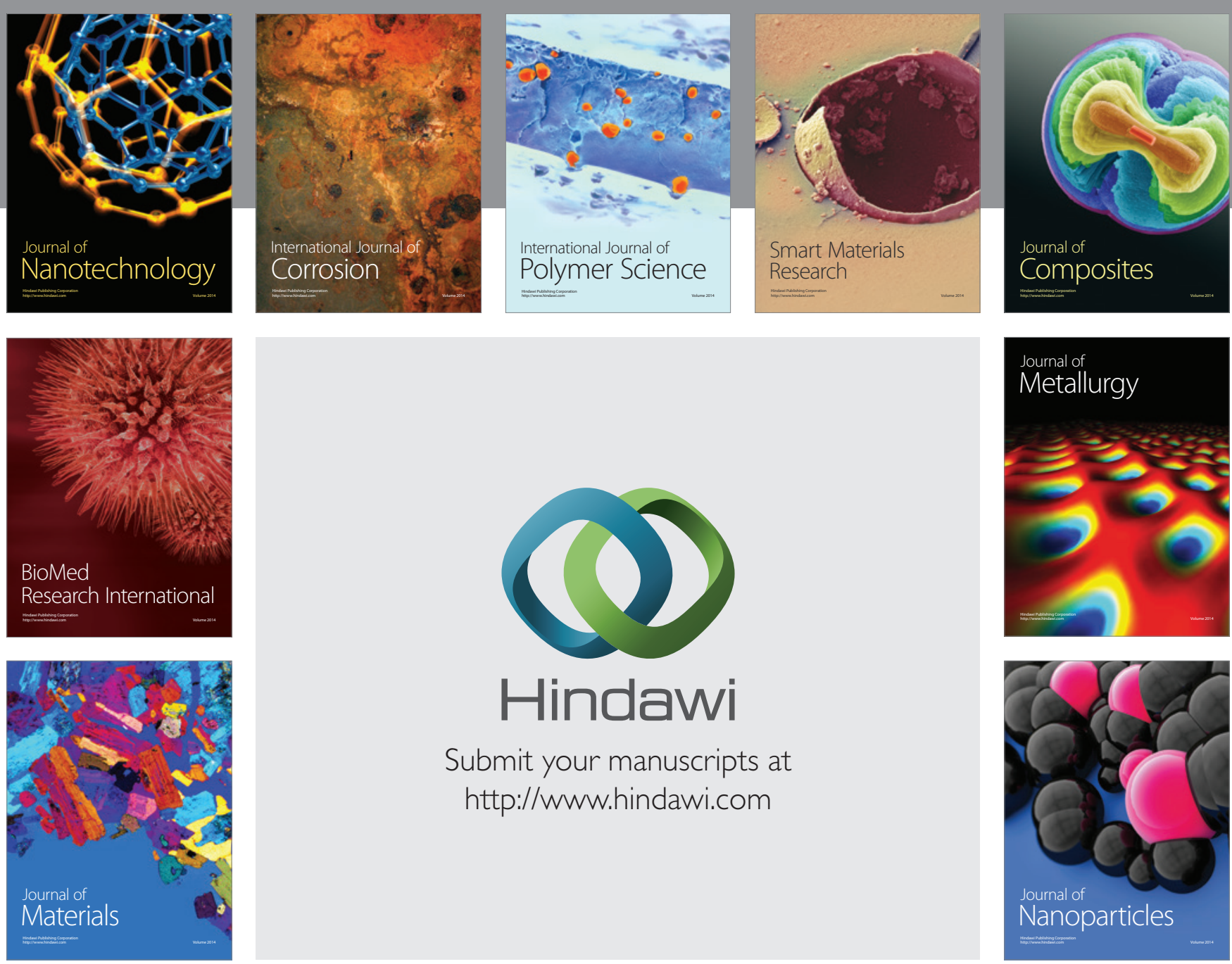

Submit your manuscripts at http://www.hindawi.com
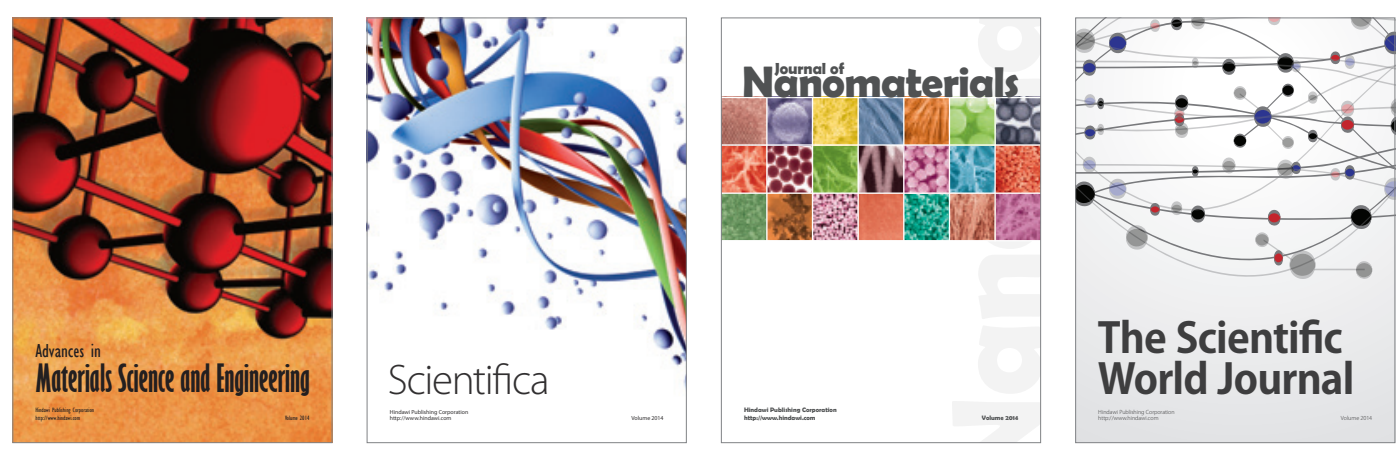

\section{The Scientific World Journal}
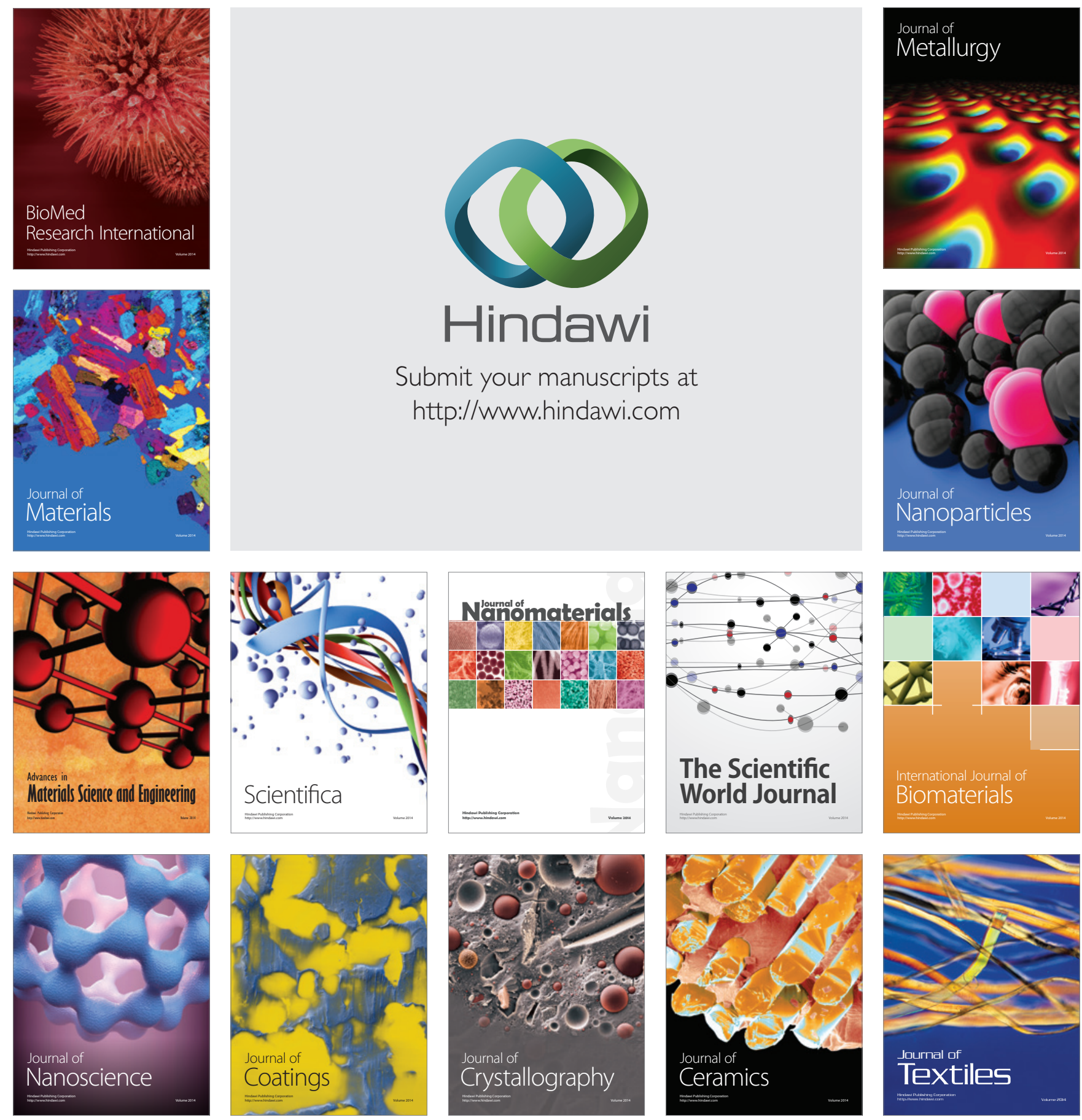